\title{
EFFECTS OF IRREGULAR NONLINEAR OCEAN WAVES ON THE DYNAMIC PERFORMANCE OF AN EXAMPLE JACK-UP STRUCTURE DURING AN EXTREME EVENT
}

\section{Authors:}

1. Jalal Mirzadeh, Centre for Offshore Foundation Systems, The UWA Oceans Institute and ARC CoE for Geotechnical Science and Engineering, University of Western Australia, Australia.

2. Mehrdad Kimiaei, Centre for Offshore Foundation Systems, The UWA Oceans Institute and ARC CoE for Geotechnical Science and Engineering, University of Western Australia, Australia.

3. Mark Jason Cassidy, Centre for Offshore Foundation Systems, The UWA Oceans Institute and ARC CoE for Geotechnical Science and Engineering, University of Western Australia, Australia.

\section{Keywords:}

1. Nonlinear Wave

2. Jack-up Platforms

3. Constrained NewWave

4. Random Sea

5. Dynamic Performance

6. Failure Probability

\section{Corresponding Author:}

Full name: Jalal Mirzadeh

Telephone: +61- 416826604

Email: jalal.mirzadeh@gmail.com; jalal.mirzadeh@uwa.edu.au 


\begin{abstract}
In this paper, the effects of the nonlinearity and irregularity of ocean waves on the nonlinear dynamic response of a jack-up structure are investigated. A finite element model of a sample jack-up platform is formulated in USFOS to include the effect of material and geometrical nonlinearity and spudcan-soil-structure nonlinear interactions. Second-order NewWave and Constrained NewWaves are developed to simulate the nonlinearity of ocean waves. The nonlinear water surface and water particle kinematics for a typical extreme wave condition are estimated and implemented in the developed model, and the results are compared in terms of deck displacements. The results obtained from the analyses indicate that the inclusion of wave nonlinearity and irregularity for the studied case produces a considerable increase in the deck displacements and in the probability of failure of the sample jack-up structure.
\end{abstract}

\title{
1 INTRODUCTION
}

Mobile jack-up units have been used in the offshore oil and gas industry since the 1950s. These structures contribute significantly to global offshore engineering activities, including the exploration and operation of offshore oil and gas fields and the servicing of fixed platforms. Since their initial employment, jack-ups have been used in deeper waters and harsher environments. Additionally, increasing interest has emerged in using these units for long-term assignments. Therefore, ensuring that these structures can safely sustain all applied loads and that the likelihood of their failure is acceptably small is crucial. Therefore, all uncertainties associated with the performance of these structures should be incorporated as precisely as possible. One of the main sources of uncertainties is the modelling of ocean waves. Ocean waves are irregular, nonlinear and directional, particularly those resulting from hurricanes [1].

The irregularity of waves illustrates that wave energy is distributed across a broad spectrum of the ocean environment, whereas deterministic regular wave theories such as Airy and Stokes' fifth-order (widely used in the calculation of wave loading) assume that all of the wave energy is concentrated in one or few particular frequency components. To achieve a more realistic simulation of wave loads, the simulation must incorporate all of the frequency components and, therefore, the randomness of the water surface.

The nonlinear nature of extreme ocean waves represents the wave-wave interaction phenomenon in a wave group, producing an asymmetric water surface which causes crests to become higher and narrower whereas the troughs become wider and shallower when compared to linear waves [2, 3 and 4]. Higher crest heights and the 
associated water particle kinematics because of the nonlinearity of extreme ocean waves can play an important role in the stability of structures by significantly increasing the wave loads, notably when a wave-in-deck is possible.

The directionality effect explains how extreme waves propagate in different directions with a wide range of energies and frequencies in each direction. This effect reduces the width of the crests (perpendicular to mean wave direction) and decreases the particle kinematics of the water in the mean wave direction [5].

However, because of the significant complexities, these characteristics of real ocean waves are not explicitly included in the conventional analysis procedures. Therefore, investigation of the effect of these phenomena on the performance of a jack-up unit in an extreme event at a specific field is required. Considering the limitations in the current practices, a more rigorous numerical method is required to accurately and realistically simulate extreme ocean waves. In a previous study [5], the authors broadly investigated the effects of the directionality of ocean waves. In this study, only the effects of the nonlinearity and the randomness of ocean waves are considered.

Limited research has been previously conducted on the effect of the nonlinearity and randomness of waves on the dynamic performance of offshore structures under the action of a hostile wave environment. Sharma and Dean [1] assessed the load reduction for a single pile and for a group of piles resulting from directional nonlinear (second-order) random waves. Smith et al. [2] also quantified the level of load reduction in a sample jack-up using a nonlinear directional NewWave and compared the results with linear NewWave and Stokes' fifth-order wave theories; consequently, the effects of randomness were neglected. Agarwal and Manuel [6] estimated the effect of nonlinear irregular waves on the base shear of a monopile wind turbine and showed an increase in loads compared to linear waves. Moreover, van der Meulen el al. [7] assessed the effect of nonlinear irregular waves on the fatigue load of a typical monopole offshore wind turbine, and that study noted a considerable increase in the loads. In all of the above studies, a numerical method based on a Fourier Transform technique was utilized to calculate the water surface and wave kinematics at different locations of the structures. In addition, Cassidy et al. $[8,9]$ considered the effect of unidirectional random waves by constraining the deterministic linear NewWave [10] into a completely random background using the Constrained NewWave (CNW) method [11]; however, the nonlinearity effects were ignored.

The objective of this paper is to perform a nonlinear dynamic time history analysis for both linear and nonlinear waves and compare the results on the performance of a typical jack-up platform. NewWave and CNW are used 
to simulate the wave actions; thereby, the effects of randomness are emphasised in the latter. The nonlinear CNW method, which accounts for the random background of ocean waves, has not been previously used to assess the effect of nonlinearity on the performance of jack-up structures. A mathematical model for simulating nonlinear waves has been developed, and the results (water surface and wave kinematics) are then implemented in a nonlinear dynamic time history analysis of a sample jack-up platform.

\section{WAVE MODELLING}

In the present study, linear and nonlinear NewWave and CNW theories are adopted in wave modelling. These wave theories are briefly described as follows.

The NewWave theory [10] is a deterministic method that accounts for the spectral composition of the sea-state. By assuming that the surface elevation can be simulated as a Gaussian random process, the expected elevation during an extreme event can be derived theoretically and the surface elevation around this extreme event is modelled by the statistically most probable shape associated with its occurrence. This is particularly useful in offshore engineering because simulating many hours of a random storm in real time is a computationally time consuming process and only a few of the wave cycles in each time series are capable of producing the extreme result [12]. The shape that is the statistically most probable and associated with the occurrence of the event is applied to model the surface elevation around this extreme event [10]. For simplicity in the numerical implementation, the NewWave shape is discretised using a finite number $(\mathrm{N})$ of sinusoidal wave components.

Because a unique relationship between the wave number and the frequency is noted, the spatial dependency can also be included, which leads to the following discrete form of the linear surface elevation $\eta_{w}^{\mathrm{I}}(\mathrm{X}, \tau)$ for the unidirectional wave:

$\eta_{w}^{I}(X, \tau)=\sum_{n=1}^{N} A_{n} \cos \left(k_{n} X-\omega_{n} \tau\right)$

$A_{n}=\frac{\alpha}{\sigma^{2}} S_{\eta \eta}\left(\omega_{n}\right) d \omega$

where $\mathrm{k}_{\mathrm{n}}$ and $\omega_{\mathrm{n}}$ represent the wave number and angular frequency of the $\mathrm{n}^{\text {th }}$ frequency component, respectively; $\alpha$ represents the NewWave crest elevation; $S_{\eta \eta}\left(\omega_{n}\right) d \omega$ represents the surface elevation spectrum, $\sigma$ is the standard deviation that corresponds to that wave spectrum; $\mathrm{X}=\mathrm{x}-\mathrm{X}_{1}$ and $\tau=\mathrm{t}-\mathrm{t}_{1}$ are the horizontal distance and time relative to the initial position $\left(\mathrm{x}_{1}\right)$ and initial time $\left(\mathrm{t}_{1}\right)$; respectively, and $\mathrm{X}=0$ and $\tau=0$ 
represent the location and time of the wave crest, respectively. Thus, the spatial field is positioned so that the crest occurs at a user-defined time and position relative to the structure.

Taylor et al. [11] and Cassidy et al. [8] showed that the CNWs, which are generated mathematically by constraining a NewWave (of a predetermined crest height) in a random time series that defines the irregular background surface elevation, can be used as an alternative to 3-hr randomly generated waves. This process is rigorously performed, in which the constrained sequence is statistically indistinguishable from the original random sequence. The application of this approach in the structural analysis of offshore facilities can provide the required extreme response that, on average, correlates with the occurrence of a large wave in a random seastate [11].

Wavelets of different wave lengths, amplitudes and periods that travel at varying speeds are superposed to generate the random water surface. For a unidirectional wave, the linear random surface elevation, $\eta_{\mathrm{r}}^{\mathrm{I}}(\mathrm{X}, \tau)$, is defined as follows:

$\eta_{r}^{\mathrm{I}}(X, \tau)=\sum_{n=1}^{N} B_{n} \cos \left(k_{n} X-\omega_{n} \tau+\varphi_{n}\right)$

where $\varphi_{\mathrm{n}}$ are the random phases uniformly distributed between 0 and $2 \pi$, and $\mathrm{B}_{\mathrm{n}}$ is the amplitude of the random wave components, which are Rayleigh random variables with a mean square related to twice the wave energy spectrum at the corresponding discrete frequency:

$\mathrm{E}\left[\mathrm{B}_{\mathrm{n}}^{2}\right]=2 \mathrm{~S}_{\eta \eta}\left(\omega_{\mathrm{n}}\right) \mathrm{d} \omega$

The linear constrained surface elevation $\eta_{\mathrm{c}}^{\mathrm{I}}(\mathrm{X}, \tau)$ is considered as follows:

$\eta_{\mathrm{c}}^{\mathrm{I}}(\mathrm{X}, \tau)=\eta_{\mathrm{r}}^{\mathrm{I}}(\mathrm{X}, \tau)+\gamma \cdot \eta_{\mathrm{w}}^{\mathrm{I}}(\mathrm{X}, \tau)+\delta \cdot \eta_{\mathrm{w}}^{\mathrm{I}}(\mathrm{X}, \tau)$

where

$\gamma=\left[1-\frac{\eta_{\mathrm{r}}^{\mathrm{I}}\left(\mathrm{x}_{1}, \mathrm{t}_{1}\right)}{\eta_{\mathrm{w}}^{\mathrm{I}}\left(\mathrm{x}_{1}, \mathrm{t}_{1}\right)}\right]$

and

$\delta=\left[\frac{\dot{\eta_{\mathrm{r}}^{\mathrm{I}}}\left(\mathrm{x}_{1}, \mathrm{t}_{1}\right)}{\mathrm{m}_{2}}\right]$

and $\eta_{\mathrm{w}}^{\mathrm{I}}$ and $\eta_{\mathrm{r}}^{\mathrm{I}}$ are the derivative of $\eta_{\mathrm{w}}^{\mathrm{I}}$ and $\eta_{\mathrm{r}}^{\mathrm{I}}$ with respect to $\tau$, respectively, and $m_{2}$ is the second spectral moment of the wave energy spectrum.

Therefore, the linear CNW water surface can be presented as follows:

$\eta_{c}^{\mathrm{I}}(X, \tau)=\sum_{n=1}^{N} B_{n} \cos \left(k_{n} X-\omega_{n} \tau+\varphi_{n}\right)+\gamma A_{n} \cos \left(k_{n} X-\omega_{n} \tau\right)+\delta A_{n} \omega_{n} \sin \left(k_{n} X-\omega_{n} \tau\right)$ 
Detail description and sample application of linear CNW with its NewWave and random wave are presented by Mirzadeh et al. [5] and [22].

The linear potential function can be calculated [1] based on the following equation:

$$
\begin{aligned}
\phi_{c}^{\mathrm{I}}(X, Z, \tau)=-\mathrm{g} \int \eta_{\mathrm{c}}^{\mathrm{I}} \frac{\cosh \mathrm{k}_{\mathrm{n}}(\mathrm{h}+\mathrm{Z})}{\cosh \mathrm{k}_{\mathrm{n}} \mathrm{h}} \mathrm{dt} \\
\quad=\mathrm{g} \sum_{\mathrm{n}=1}^{\mathrm{N}} \frac{\cosh \mathrm{k}_{\mathrm{n}}(\mathrm{h}+\mathrm{Z})}{\cosh \mathrm{k}_{\mathrm{n}} \mathrm{h}}\left(\frac{\mathrm{B}_{\mathrm{n}}}{\omega_{\mathrm{n}}} \sin \left(\mathrm{k}_{\mathrm{n}} \mathrm{X}-\omega_{\mathrm{n}} \tau+\varphi_{\mathrm{n}}\right)-\frac{\gamma \mathrm{A}_{\mathrm{n}}}{\omega_{\mathrm{n}}} \sin \left(\mathrm{k}_{\mathrm{n}} \mathrm{X}-\omega_{\mathrm{n}} \tau\right)\right. \\
\left.+\delta \mathrm{A}_{\mathrm{n}} \cos \left(\mathrm{k}_{\mathrm{n}} \mathrm{X}-\omega_{\mathrm{n}} \tau\right)\right)
\end{aligned}
$$

which satisfies the following equations [1].

$\nabla^{2} \phi=0$

$\frac{\partial \phi}{\partial \mathrm{Z}}=0 ; \mathrm{Z}=-\mathrm{h}$

where $\mathrm{h}$ and $\mathrm{Z}$ are the water depth and vertical coordinate related to the still water level, respectively (Figure 1).

The nonlinear potential function and water surface can be presented as follows:

$\phi(X, Z, \tau)=\phi^{\mathrm{I}}(\mathrm{X}, \mathrm{Z}, \tau)+\phi^{\mathrm{II}}(\mathrm{X}, \mathrm{Z}, \tau)$

$\eta(X, \tau)=\eta^{I}(X, \tau)+\eta^{I I}(X, \tau)$

where $\phi^{\mathrm{II}}(\mathrm{X}, \mathrm{Z}, \tau)$ and $\eta^{\mathrm{II}}(\mathrm{X}, \tau)$ are the second-order contributions of the potential function and water surface, respectively.

The second-order contribution of the potential function can be generated based on the linear potential function at $\mathrm{Z}=0[1]$ using the following function:

$\frac{\partial^{2} \phi^{\mathrm{II}}}{\partial \tau^{2}}+\mathrm{g} \frac{\partial \phi^{\mathrm{II}}}{\partial \mathrm{Z}}=-\frac{\partial}{\partial \tau}\left(\nabla \phi^{\mathrm{I}} \cdot \nabla \phi^{\mathrm{I}}\right)-\eta^{\mathrm{I}} \frac{\partial}{\partial \mathrm{Z}}\left(\frac{\partial^{2} \phi^{\mathrm{I}}}{\partial \tau^{2}}+\mathrm{g} \frac{\partial \phi^{\mathrm{I}}}{\partial \mathrm{Z}}\right)$

By substituting for the linear constrained NewWave potential function $\phi_{c}^{\mathrm{I}}$ and water surface $\eta_{\mathrm{c}}^{\mathrm{I}}$ in Equation 14 , the second-order contribution of the constrained NewWave $\phi_{c}^{\mathrm{II}}$ is obtained by the authors as follows:

$\phi_{\mathrm{c}}^{\mathrm{II}}=\phi_{+}^{\mathrm{II}}+\phi_{-}^{\mathrm{II}}$

where 


$$
\begin{aligned}
& \phi_{ \pm}^{\mathrm{II}}=\sum_{m=1}^{N} \sum_{n=1}^{N} \mathrm{D}_{\mathrm{mn}}^{ \pm} \frac{\cosh \mathrm{k}_{\mathrm{mn}}^{ \pm}(\mathrm{h}+\mathrm{z})}{\cosh \mathrm{k}_{\mathrm{mn}}^{ \pm} \mathrm{h}}\left\{\mathrm{A}_{\mathrm{m}} \mathrm{A}_{\mathrm{n}}\left(\omega_{\mathrm{m}} \pm \omega_{\mathrm{n}}\right) \gamma \delta \cos \left(\tau\left(\omega_{\mathrm{m}} \pm \omega_{\mathrm{n}}\right)-\left(\mathrm{k}_{\mathrm{m}} \pm \mathrm{k}_{\mathrm{n}}\right) \mathrm{X}\right)\right. \\
& \pm A_{n} B_{m} \omega_{n} \delta \cos \left(\tau\left(\omega_{m} \pm \omega_{n}\right)-\left(k_{m} \pm k_{n}\right) X-\varphi_{m}\right) \\
& +A_{m} B_{n} \omega_{m} \delta \cos \left(\tau\left(\omega_{m} \pm \omega_{n}\right)-\left(k_{m} \pm k_{n}\right) X-\varphi_{n}\right) \\
& +A_{m} A_{n}\left(\gamma^{2} \mp \omega_{m} \omega_{n} \delta^{2}\right) \sin \left(\tau\left(\omega_{m} \pm \omega_{n}\right)-\left(k_{m} \pm k_{n}\right) X\right) \\
& +A_{n} B_{m} \gamma \sin \left(\tau\left(\omega_{m} \pm \omega_{n}\right)-\left(k_{m} \pm k_{n}\right) X-\varphi_{m}\right) \\
& +A_{m} B_{n} \gamma \sin \left(\tau\left(\omega_{m} \pm \omega_{n}\right)-\left(k_{m} \pm k_{n}\right) X \pm \varphi_{n}\right) \\
& \left.+\mathrm{B}_{\mathrm{m}} \mathrm{B}_{\mathrm{n}} \sin \left(\tau\left(\omega_{\mathrm{m}} \pm \omega_{\mathrm{n}}\right)-\left(\mathrm{k}_{\mathrm{m}} \pm \mathrm{k}_{\mathrm{n}}\right) X-\left(\varphi_{m} \pm \varphi_{n}\right)\right)\right\}
\end{aligned}
$$

and

$$
\begin{aligned}
& \mathrm{D}_{\mathrm{mn}}^{ \pm}=\frac{-1}{4 \omega_{\mathrm{m}} \omega_{\mathrm{n}}}\left\{\left(\omega_{\mathrm{m}} \pm \omega_{\mathrm{n}}\right)^{2}-\mathrm{gk}_{\mathrm{mn}}^{ \pm} \tanh \mathrm{k}_{\mathrm{mn}}^{ \pm} \mathrm{h}\right\} \\
& \times \mathrm{g}\left\{\mathrm{g}\left( \pm \mathrm{k}_{\mathrm{n}}{ }^{2} \omega_{\mathrm{m}}+2 \mathrm{k}_{\mathrm{m}} \mathrm{k}_{\mathrm{n}}\left(\omega_{\mathrm{m}} \pm \omega_{\mathrm{n}}\right) \mp 2 \mathrm{R}_{\mathrm{m}} \mathrm{R}_{\mathrm{n}}\left(\omega_{\mathrm{m}} \pm \omega_{\mathrm{n}}\right)+\mathrm{k}_{\mathrm{m}}{ }^{2} \omega_{\mathrm{n}}\right)\right. \\
&\left.\mp \omega_{\mathrm{m}} \omega_{\mathrm{n}}\left( \pm \mathrm{R}_{\mathrm{m}} \omega_{\mathrm{m}}+\mathrm{R}_{\mathrm{n}} \omega_{\mathrm{n}}\right)\right\}
\end{aligned}
$$

and

$\mathrm{k}_{\mathrm{mn}}^{ \pm}=\left|\mathrm{k}_{\mathrm{m}} \pm \mathrm{k}_{\mathrm{n}}\right|$

$\mathrm{R}_{\mathrm{m}}=\mathrm{k}_{\mathrm{m}} \tanh \mathrm{k}_{\mathrm{m}} \mathrm{h}=\frac{\omega_{\mathrm{m}}{ }^{2}}{\mathrm{~g}}$

The second-order contribution of the water surface can be generated at $Z=0$ [1] based on the following function:

$\eta^{\mathrm{II}}=-\frac{1}{\mathrm{~g}}\left(\frac{\partial \phi^{\mathrm{II}}}{\partial \tau}+\frac{1}{2}\left(\nabla \phi^{\mathrm{I}} \cdot \nabla \phi^{\mathrm{I}}\right)+\eta^{\mathrm{I}} \frac{\partial^{2} \phi^{\mathrm{I}}}{\partial \mathrm{Z} \partial \tau}\right)$

Therefore, the resulting expression for the second-order contribution of the constrained NewWave $\eta_{c}^{\text {II }}$ is obtained by authors as follows:

$\eta_{\mathrm{c}}^{\mathrm{II}}=\eta_{+}^{\mathrm{II}}+\eta_{-}^{\mathrm{II}}$

where 


$$
\begin{aligned}
& \eta_{ \pm}^{\mathrm{II}}=\sum_{\mathrm{m}=1}^{\mathrm{N}} \sum_{\mathrm{n}=1}^{\mathrm{N}} \mathrm{E}_{\mathrm{mn}}^{ \pm}\left\{\mathrm{A}_{\mathrm{m}} \mathrm{A}_{\mathrm{n}}\left(\gamma^{2} \mp \omega_{\mathrm{m}} \omega_{\mathrm{n}} \delta^{2}\right) \cos \left(\tau\left(\omega_{\mathrm{m}} \pm \omega_{\mathrm{n}}\right)-\left(\mathrm{k}_{\mathrm{m}} \pm \mathrm{k}_{\mathrm{n}}\right) X\right)\right. \\
& +A_{n} B_{m} \gamma \cos \left(\tau\left(\omega_{m} \pm \omega_{n}\right)-\left(k_{m} \pm k_{n}\right) X-\varphi_{m}\right) \\
& +A_{m} B_{n} \gamma \cos \left(\tau\left(\omega_{m} \pm \omega_{n}\right)-\left(k_{m} \pm k_{n}\right) X \mp \varphi_{n}\right) \\
& +B_{m} B_{n} \cos \left(\tau\left(\omega_{m} \pm \omega_{n}\right)-\left(k_{m} \pm k_{n}\right) X-\left(\varphi_{m} \pm \varphi_{n}\right)\right) \\
& -A_{m} A_{n}\left(\omega_{m} \pm \omega_{n}\right) \gamma \delta \sin \left(\tau\left(\omega_{m} \pm \omega_{n}\right)-\left(k_{m} \pm k_{n}\right) X\right) \\
& \mp A_{n} B_{m} \omega_{n} \delta \sin \left(\tau\left(\omega_{m} \pm \omega_{n}\right)-\left(k_{m} \pm k_{n}\right) X-\varphi_{m}\right) \\
& \left.-A_{m} B_{n} \omega_{m} \delta \sin \left(\tau\left(\omega_{m} \pm \omega_{n}\right)-\left(k_{m} \pm k_{n}\right) X \mp \varphi_{n}\right)\right\}
\end{aligned}
$$

and

$$
\begin{aligned}
\mathrm{E}_{\mathrm{m} n}^{ \pm}=\frac{1}{4 \omega_{\mathrm{m}} \omega_{\mathrm{n}}} & \left\{\left(\omega_{\mathrm{m}} \pm \omega_{\mathrm{n}}\right)^{2}-\mathrm{g} \mathrm{k} \mathrm{mn}_{\mathrm{m}}^{ \pm} \tanh \mathrm{k}_{\mathrm{mn}}^{ \pm} \mathrm{h}\right\} \\
\times & \left\{( \omega _ { \mathrm { m } } \pm \omega _ { \mathrm { n } } ) \left(\mathrm{g}\left( \pm \mathrm{k}_{\mathrm{n}}{ }^{2} \omega_{\mathrm{m}}+\mathrm{k}_{\mathrm{m}} \mathrm{k}_{\mathrm{n}}\left(\omega_{\mathrm{m}} \pm \omega_{\mathrm{n}}\right) \mp \mathrm{R}_{\mathrm{m}} \mathrm{R}_{\mathrm{n}}\left(\omega_{\mathrm{m}} \pm \omega_{\mathrm{n}}\right)+\mathrm{k}_{\mathrm{m}}{ }^{2} \omega_{\mathrm{n}}\right)\right.\right. \\
+ & \left.\omega_{\mathrm{m}} \omega_{\mathrm{n}}\left(\mathrm{R}_{\mathrm{n}} \omega_{\mathrm{m}} \pm \mathrm{R}_{\mathrm{m}} \omega_{\mathrm{n}}\right)\right) \\
& \left.+\mathrm{gk} \mathrm{k}_{\mathrm{m} n}^{ \pm}\left(\mathrm{g}\left(\mathrm{k}_{\mathrm{m}} \mathrm{k}_{\mathrm{n}} \mp \mathrm{R}_{\mathrm{m}} \mathrm{R}_{\mathrm{n}}\right)-\left(\mathrm{R}_{\mathrm{m}}+\mathrm{R}_{\mathrm{n}}\right) \omega_{\mathrm{m}} \omega_{\mathrm{n}}\right) \tanh \mathrm{k}_{\mathrm{m} n}^{ \pm} \mathrm{h}\right\}
\end{aligned}
$$

The water particle kinematics can be calculated based on the following functions:

$$
\begin{aligned}
& \mathrm{u}(\mathrm{X}, \mathrm{Z}, \tau)=\frac{\partial \phi}{\partial \mathrm{X}} \\
& \mathrm{w}(\mathrm{X}, \mathrm{Z}, \tau)=\frac{\partial \phi}{\partial \mathrm{Z}} \\
& \mathrm{a}_{\mathrm{X}}(\mathrm{X}, \mathrm{Z}, \tau)=\frac{\partial^{2} \phi}{\partial \mathrm{X} \partial \tau} \\
& \mathrm{a}_{\mathrm{Z}}(\mathrm{X}, \mathrm{Z}, \tau)=\frac{\partial^{2} \phi}{\partial \mathrm{Z} \partial \tau}
\end{aligned}
$$

where $\mathrm{u}$ and $\mathrm{w}$ are the horizontal and vertical velocities, respectively, and $\mathrm{a}_{\mathrm{x}}$ and $\mathrm{a}_{\mathrm{z}}$ are the horizontal and vertical accelerations, respectively.

The water particle kinematics above the still water level can be estimated using different methods. Stansberg et al. [13] assessed the horizontal velocity at the extreme wave using different methods such as Wheeler's [14] and second-order models. For a steep crest in deep water, the second-order model provides the best estimation for the velocity of the water column at all levels. The second-order horizontal velocity at any elevation under the crest is formulated as follows [13]: 


$$
\begin{cases}u(Z)=u^{\mathrm{I}}(\mathrm{Z})+\mathrm{u}^{\mathrm{II}}(\mathrm{Z}) & ; \mathrm{Z} \leq 0 \\ \mathrm{u}(\mathrm{Z})=\mathrm{u}^{\mathrm{I}}(0)+\mathrm{Z}\left(\frac{\partial \mathrm{u}^{\mathrm{I}}}{\partial \mathrm{Z}}\right)_{\mathrm{Z}=0}+\mathrm{u}^{\mathrm{II}}(0) ; \mathrm{Z}>0\end{cases}
$$

Similar expressions exist for the vertical velocity and horizontal and vertical accelerations [15].

In this paper, the Wheeler's and second-order methods are used to calculate water particle kinematics for linear and nonlinear waves, respectively.

The nonlinear potential function and water surface of the NewWave can be generated when considering $B_{n}$ and $\delta$ equal to zero in the CNW equations. More detailed descriptions of simulating NewWave and CNW can be found in Tromans et al. [10], Taylor et al. [11], Cassidy [12] and Cassidy et al. [8, 9], and detailed information about nonlinear waves were previously presented [16, 1].

\section{CASE STUDY}

The proposed methodology to calculate the water surface and wave kinematics is applied to determine the hydrodynamic forces on a sample jack-up platform located at a water depth of $106.7 \mathrm{~m}$ using the USFOS software [17]. The main aim of this case study is to investigate how the second-order effect for a typical extreme wave condition can influence overall response of the sample jack-up platform. Results of this pilot study underpin the basis for future sensitivity analyses for different input parameters. A general view of this platform is presented in Figure 1. This jack-up platform is symmetrical in three axes and consists of a hull structure supported by three main legs that rest on the seafloor through spudcan foundations. The jack-up legs (with a centre-to-centre distance of $46 \mathrm{~m}$ ) are composed of three vertical members that are stiffened through X-braces and form a triangular truss structure. The top elevation is $146.1 \mathrm{~m}$ above the seabed. The hull structure is modelled by equivalent linear general beam sections and is raised to an elevation of $131.7 \mathrm{~m}$ above the seafloor during operation. The nonlinearity of the leg-hull connections is not included in the model. The total self-weight of the jack-up platform is 134.2 MN. The soil type is assumed to be sand with a 35-degree friction angle. The diameter of the spudcan is $17 \mathrm{~m}$, the apex angle is 86 degrees, and the preload is assumed to be $120 \mathrm{MN}$ (i.e., approximately 2.7 times the self-weight reaction in each leg). The first three natural periods of the jack-up structure are $7.70 \mathrm{~s}$ (sway in the $\mathrm{X}$ direction), $7.69 \mathrm{~s}$ (sway in the $\mathrm{Y}$ direction), and $6.82 \mathrm{~s}$ (rotation about the vertical axis).

In this study, the storm condition is represented by a JONSWAP spectrum with a significant wave height of $\mathrm{H}_{\mathrm{s}}=17.46 \mathrm{~m}$ and a peak period $\mathrm{T}_{\mathrm{p}}=17.22 \mathrm{~s}$ (representing a sample Northern North Sea extreme condition), 
which is discretized to 1024 frequency components with the frequency intervals of $0.001 \mathrm{rad} / \mathrm{sec}$ and the cut-off frequency of $4 f_{p}$, where $f_{p}$ is the peak frequency of the spectrum. The duration of the NewWave and CNW is $300 \mathrm{~s}$, and the peak occurs at $\mathrm{t}=150 \mathrm{~s}$ at the hull centre $(\mathrm{x}=0 \mathrm{~m})$ as presented in Figure 1 . The waves are considered the only environmental load with no applied wind or current and the effects of marine growth is ignored. The water surface and wave kinematics for the first and last $50 \mathrm{~s}$ of the CNW duration (i.e., about three times $T_{p}$ ) are zero-tapered by using a cosine function.

The time history of the water surface and wave kinematics, estimated based on the formulation in Section 2, are implemented in USFOS [17] to calculate the hydrodynamic forces on the structural members. For this aim, USFOS employs the extended Morison equation which incorporates the relative motions. The hydrodynamic coefficient values for tubular sections in the Morison equation are considered to be $C_{D}=0.7$ and $C_{M}=2.0$ based on ISO/TR 19905-2 [18], and the wave kinematic reduction factor $\left(\mathrm{K}_{\mathrm{rf}}\right)$ is equal to 0.9. Nonlinear dynamic analyses are conducted with the waves acting in the X-direction such that the overturning moment because of the maximum crest results in compressive forces in one leeward leg and tensile forces in two windward legs as shown in Figure 1.

In this study, both linear and nonlinear waves are applied on the sample structure, and the results are compared. In addition, an alternative simplified method to calculate the water particle kinematics is introduced, and the results from this method are also included in the comparisons. In this method, the time histories of the nonlinear water surface at all locations are discretised into a finite set of wave components using the Fourier Transform. These wave components are then used individually to estimate the water particle kinematics at each location using Wheeler's method. It should be noted that the simplified water surfaced is exactly the same as nonlinear water surface. This method is considerably less time consuming when compared to calculating the water particle kinematics based on the second-order method.

The structural nonlinearity of the jack-up elements, which are expected to experience substantial deformation and displacement under the action of extreme environmental loading, are modelled using specially developed beam elements in USFOS that can simulate large displacements and deformations considering material and geometrical nonlinearities. The material nonlinearity is considered using a stress-resultant plasticity approach, in which the kinematic hardening model is used to characterise the yield and plastic potential functions. Geometrical nonlinearities at the local level (i.e., individual members) and global level are considered by updating the structural geometry as the analysis proceeds $[17,19]$. 
The foundation nonlinearity is considered using a predefined hardening plasticity method in USFOS to model the soil-spudcan interaction [20]. This model consists of a yield function to evaluate the bearing capacity and a flow rule to calculate the plastic deformations. The yield function depends on the resultant horizontal and vertical loads, the bending moments in the $3 \mathrm{D}$ model $(\mathrm{H}, \mathrm{V}$ and $\mathrm{M})$ and the corresponding plastic rotation $\left(\theta_{\mathrm{p}}\right)$ of the spudcan. This function is based on a two-surface concept (the initial yield surface and the failure surface) and a hardening rule which provides a smooth transition from the initial yield surface to the failure surface in the intermediate zone. The hardening rule is a function of the plastic rotation of the spudcan. Detailed information about the hardening plasticity model in USFOS is presented by Amdahl et al. [20] and van Langen et al. [21].

\section{RESULTS AND DISCUSSION}

Results from the nonlinear dynamic analyses on the sample jack-up structure subjected to a typical extreme sea conditions are studied in this section. The structural response is evaluated in terms of the deck displacement of the jack-up which is representative of all nonlinearities in the structure and the foundation and the dynamic reaction of the structure to the applied wave loads [5]. In this study, the horizontal deck displacement at $\mathrm{x}=0.0$ m (centre of the hull) is used to investigate the effects of wave nonlinearity and irregularity on the overall performance of the jack-up structure.

The calculation of the water surface elevation and wave kinematics requires a fine grid spacing in the wave domain to accurately capture all wave characteristics. The horizontal domain should cover the entire structure, and the vertical domain must extend from the seabed to the instantaneous water surface. The grid spacing is considered as follows and contains 2635 nodes:

- Horizontal: $\Delta \mathrm{x}=2.5 \mathrm{~m}$

- $\quad$ Vertical (Elevation $\mathrm{z}=0$ is the still water level):

o $\Delta \mathrm{z}=5.0 \mathrm{~m}$ from seabed to $\mathrm{z}=-20.0 \mathrm{~m}$, which is lower than the deepest trough;

o $\Delta \mathrm{z}=1.0 \mathrm{~m}$ from $\mathrm{z}=-20.0 \mathrm{~m}$ to $\mathrm{z}=18.0 \mathrm{~m}$, which is lower than the maximum crest elevation of linear waves; and

o $\quad \Delta \mathrm{z}=0.1 \mathrm{~m}$ from $\mathrm{z}=18.0 \mathrm{~m}$ to $\mathrm{z}=21.4 \mathrm{~m}$, which is higher than the maximum crest elevation of nonlinear waves.

To ensure that this grid spacing is fine enough to capture all rapid surface variations, the response of the sample jack-up under a nonlinear NewWave with a maximum linear crest height of $18.7 \mathrm{~m}$ in the above mentioned grid 
dimension is compared to the response of the structure in a wave domain with half the grid spacing. A comparison of the results showed negligible differences, confirming that the selected grid sizes are closely spaced and can efficiently capture the wave characteristics. Therefore, the selected grid sizes are used for the analyses.

\subsection{Results from the NewWave Model}

Figure 2 illustrates the linear and nonlinear NewWave profiles at the location of $\mathrm{x}=0.0 \mathrm{~m}$ with a maximum linear crest height of $18.7 \mathrm{~m}$. As shown, the nonlinearity effects have flattened the wave troughs (decreased the maximum trough depth from $16.7 \mathrm{~m}$ to $14.8 \mathrm{~m}$ ) and sharpened the crests (increased the maximum crest height from $18.7 \mathrm{~m}$ to $21.1 \mathrm{~m}$ ), but do not affect the wave period. Figure 3 compares the amplitude spectra of the linear and nonlinear NewWave water surfaces. The spectrum for the nonlinear wave displays additional amplitude in low and high frequencies. The low frequency energy, where the linear spectrum has no amplitude, is added due to the second-order difference contribution. Additionally, a small peak develops in the vicinity of twice the frequency of the peak amplitude of the linear spectrum because of the second-order sum contribution.

Figure 4 illustrates the space plot of the NewWave water surface elevation generated based on the linear and nonlinear methods. Figure 5 compares the horizontal velocity profile of the three employed models at the location and time of the maximum crest height. The estimated horizontal velocity of the nonlinear wave in the lower part of the water column is less than that of the linear and simplified methods. However, the middle portion of the velocity profile for the nonlinear method is generally higher than the other two methods, except near the water surface at the crest location. At this location, the horizontal velocity from the simplified method approaches the nonlinear results. Compared to the linear method, the simplified method produces a better estimation of the horizontal velocity profile. However, to obtain a better understanding of the effects of the nonlinear method, the horizontal velocity during the extreme crest height at different locations is assessed. Figure 6 depicts the space domain of the horizontal velocity calculated based on different methods. The simplified method provides a better estimation of the nonlinear horizontal velocity at all locations compared to linear waves.

Figure 7 represents the deck displacement time history of the sample jack-up subjected to NewWaves generated based on the different methods. The response because of the nonlinear method is considerably higher than the linear and simplified methods. However, it can be seen that the simplified method represents a better estimation of the response of nonlinear method. 


\subsection{Results from the CNW Model}

To inspect the effects of the irregularity and nonlinearity of waves, linear and nonlinear CNWs were generated and applied to the structure. Figure 8 and Figure 9 present the time history and space plot of the water surface of a sample CNW with a linear NewWave crest height of $18.7 \mathrm{~m}$. As illustrated, the water surfaces follow the identical trend as those of NewWaves presented in Figure 2 and Figure 4. Figure 10 displays the time history of the deck displacement of the sample jack-up subjected to CNWs based on the three employed methods. The results from the CNWs are similar to the results from the NewWaves in Figure 7. The structural response under a nonlinear CNW is considerably higher than that of the linear and simplified methods; the linear method gives the lowest results.

To assess the effect of different random backgrounds of CNWs on the structural response statistics, 125 CNWs with a linear NewWave crest height of $18.7 \mathrm{~m}$ were generated using the different methods and applied to the sample jack-up. Although no overall failures occurred under the applied 125 linear method CNWs, 23 and 4 nonlinear and simplified CNWs respectively produced failure in the sample jack-up. All failures occurred because of the loss of overturning stability.

The statistical results were extracted for 102 analyses cases in which no failure occurred for any of the three employed methods. These results can be characterised reasonably well using the Weibull distribution function [22] for the maximum deck displacements in the nonlinear cases (Figure 11). Figure 12 compares the Weibull distribution of the maximum deck displacements resulting from the different methods. This figure demonstrates that the inclusion of wave nonlinearity can considerably increase the structural responses. This analysis shows that the simplified method leads to better estimation of the structural response compared to linear method. Additionally, these two methods produce a response that is considerably less than the overall response under nonlinear waves.

To better understand the effect of wave nonlinearity on the results, the distributions of the ratio of the maximum responses from the nonlinear and simplified methods to those of the linear method were estimated using a Weibull distribution (Figure 13). The mean value of the ratio of the maximum response from the simplified to linear methods is equal to 1.12 and this ratio is equal to 1.24 for the nonlinear method compared against the linear methods which shows that the simplified method fails to predict the nonlinearity of ocean waves. 


\subsection{Effect of Nonlinearity and Irregularity on the Dynamic Amplification Factor (DAF)}

Irregular nonlinear waves were shown to have a different frequency content compared to linear waves. When the effects of irregularity and nonlinearity are included in the wave analyses, the structure is excited with different frequency contents, indicating that the dynamic effects from the wave loads are different. These dynamic effects can be assessed in terms of a Dynamic Amplification Factor (DAF), which can be estimated by comparing the maximum response obtained from the dynamic and the quasi-static analyses. A previous study by the authors [5] has shown that the maximum deck displacement can be efficiently used as the response variable to estimate the DAF.

The DAFs were calculated for 102 non-failing CNWs from the different methods. Figure 14 compares the Weibull distribution of the DAFs with their statistical properties. For the sample jack-up, the DAF estimated for the nonlinear CNWs is lower than the DAF for the other two methods. However, the simplified method gives a better estimation of the nonlinear method compared to linear method. In addition, the DAF for the nonlinear method is less than one for a few cases, indicating that the maximum dynamic response is less than the maximum static response.

The DAF depends on the direction of inertia and damping induced forces in comparison to the wave load direction and the nonlinearities of the system. The DAF will be less than one when the direction of the resultant of inertial and damping forces is opposite to the applied wave loads. However, the DAF value will be greater than one when the resultant of inertial and damping forces act in the identical direction as the wave loads.

\section{SUMMARY AND CONCLUSIONS}

The effects of wave nonlinearity and irregularity for a typical extreme wave load on the performance of a sample dynamically sensitive jack-up structure are investigated using linear and nonlinear NewWave and CNW theories. However, it should be noted that the presented results are based on a sample jack-up, assumed sea-state and one crest location only and they can be different for other conditions. Based on the results outlined in this paper, the following points are highlighted:

- $\quad$ The nonlinearity effects flatten the wave troughs and sharpen the crests, but do not affect the wave period. As a result, the nonlinearity effects decrease the crest and increase the trough lengths. The results from both the NewWave and CNW models confirm this behaviour. 
- The nonlinearity effects cause additional energy in low and high frequencies which can have considerable effects on the response of the structure depending on their natural period.

- The inclusion of wave nonlinearity can increase the maximum deck displacement of the structure. For the studied sample jack-up, the nonlinear wave method (on average) results in a $24 \%$ increase in the maximum deck displacement.

- $\quad$ The nonlinearities in ocean waves can change the probability of failure of structures at extreme events. For the sample structure and applied sea-state, no failure occurred because of the linear waves, but 23 out of 125 (18\%) nonlinear waves result in overall failure of the platform.

- $\quad$ The proposed simplified method for modelling the wave nonlinearity, in which the wave kinematics are regenerated by Fourier components of the nonlinear water surface at different locations, fails to predict the effect of nonlinear waves on the response of the sample structure.

- $\quad$ The wave nonlinearities can change the DAF because the frequency content of waves, water surface and wave kinematics are different in comparison with linear waves. For the sample jack-up platform, the mean value of DAF decreased from 1.367 for linear waves to 1.114 when nonlinear effects are included.

\section{NOMENCLATURE}

$A_{n} \quad$ Amplitude of the NewWave components

$\mathrm{a}_{\mathrm{x}} \quad$ Horizontal acceleration

$\mathrm{a}_{\mathrm{z}} \quad$ Vertical acceleration

$\mathrm{B}_{\mathrm{n}} \quad$ Amplitude of the random wave components

$\mathrm{C}_{\mathrm{D}} \quad$ Drag coefficient

$\mathrm{C}_{\mathrm{M}} \quad$ Inertia coefficient

DAF Dynamic amplification factor

CNW Constrained NewWave

$\mathrm{D}_{\mathrm{mn}}^{ \pm} \quad$ Intermediate parameter in definition of $\phi_{ \pm}^{\mathrm{II}}$

E[ ] Mean value

$\mathrm{E}_{\mathrm{mn}}^{ \pm} \quad$ Intermediate parameter in definition of $\eta_{ \pm}^{\mathrm{II}}$

$f_{p} \quad$ Peak frequency of the wave energy spectrum

g Gravitational constant 
h Water depth

H Horizontal load of spudcan

$\mathrm{H}_{\mathrm{s}} \quad$ Significant wave height of the wave energy spectrum

$\mathrm{k}_{\mathrm{n}} \quad$ Wave number of the $\mathrm{n}^{\text {th }}$ frequency component

$\mathrm{K}_{\mathrm{rf}} \quad$ Wave kinematic reduction factor

$\mathrm{k}_{\mathrm{mn}}^{ \pm} \quad$ Second-order wave numbers

$\mathrm{N} \quad$ Number of wave components

$\mathrm{m}_{2} \quad$ Second spectral moment of the wave energy spectrum

M Bending moment of spudcan

$\mathrm{R}_{\mathrm{m}} \quad$ Intermediate parameter in definition $\phi_{ \pm}^{\mathrm{II}}$ and $\eta_{ \pm}^{\mathrm{II}}$

$S_{\eta \eta} \quad$ Wave energy spectrum

t Time

$\mathrm{t}_{1} \quad$ Initial time

$T_{p} \quad$ Peak period of the wave energy spectrum

u Horizontal velocity

$\mathrm{u}^{\mathrm{I}} \quad$ Linear horizontal velocity

$\mathrm{u}^{\mathrm{II}} \quad$ Second-order contribution of horizontal velocity

V Vertical load of spudcan

w Vertical velocity

x Horizontal distance

$\mathrm{x}_{1} \quad$ Initial position

$\mathrm{X}$ Horizontal distance relative to the initial position $\left(\mathrm{x}_{1}\right)$

Z Vertical coordinate related to the still water level

$\alpha \quad$ NewWave crest elevation

$\gamma \quad$ Intermediate parameter in definition of $\eta_{c}^{I}$

$\delta \quad$ Intermediate parameter in definition of $\eta_{c}^{I}$

$\Delta \mathrm{x} \quad$ Horizontal grid spacing

$\Delta \mathrm{z} \quad$ Vertical grid spacing

$\eta \quad$ Surface elevation

$\eta^{\mathrm{I}} \quad$ Linear surface elevation

$\eta^{\text {II }} \quad$ Second-order contributions of the surface elevation

$\eta_{\mathrm{c}}^{\mathrm{I}} \quad$ Linear Constrained NewWave surface elevation 
$\eta_{\mathrm{r}}^{\mathrm{I}} \quad$ Linear random surface elevation

$\eta_{\mathrm{w}}^{\mathrm{I}} \quad$ Linear NewWave surface elevation

$\eta_{\mathrm{c}}^{\text {II }} \quad$ Second-order contribution of the constrained NewWave surface elevation

$\eta_{+}^{\text {II }} \quad$ Second-order sum frequency contribution of the constrained NewWave surface elevation

$\eta_{-}^{\text {II }} \quad$ Second-order difference frequency contribution of the constrained NewWave surface elevation

$\eta_{\mathrm{w}}^{\mathrm{I}} \quad$ Derivative of $\eta_{\mathrm{w}}^{\mathrm{I}}$ with respect to $\tau$

$\dot{\eta_{\mathrm{r}}^{\mathrm{I}}} \quad$ Derivative of $\eta_{\mathrm{r}}^{\mathrm{I}}$ with respect to $\tau$

$\theta_{\mathrm{p}} \quad$ Plastic rotation of spudcan

$\sigma \quad$ Standard deviation corresponding to the wave energy spectrum

$\tau \quad$ Time relative to the initial time $\left(\mathrm{t}_{1}\right)$

$\varphi_{\mathrm{n}} \quad$ Random phase of the $\mathrm{n}^{\text {th }}$ frequency component

$\phi \quad$ Potential function

$\phi^{\mathrm{I}} \quad$ Linear potential function

$\phi_{\mathrm{c}}^{\mathrm{I}} \quad$ Linear potential function of the constrained NewWave

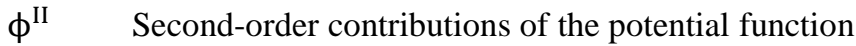

$\phi_{\mathrm{c}}^{\mathrm{II}} \quad$ Second-order contribution of the constrained NewWave potential function

$\phi_{+}^{\mathrm{II}} \quad$ Second-order sum frequency contribution of the constrained NewWave potential function

$\phi_{-}^{\text {II }} \quad$ Second-order difference frequency contribution of the constrained NewWave potential function

$\omega_{\mathrm{n}} \quad$ Angular frequency of the $\mathrm{n}^{\text {th }}$ frequency component

\section{ACKNOWLEDGMENTS}

This study was performed with the support from the Australian Research Council (ARC) Centre of Excellence for Geotechnical Science and Engineering, the ARC Laureate Fellowship scheme and the Lloyd's Register Foundation (LRF). LRF is a UK registered charity and sole shareholder of Lloyd's Register Group Ltd, which invests in science, engineering and technology for public benefit worldwide. This support is appreciated. The helpful advice and comments from Dr. Tore Holmås of USFOS A/S and Prof. Jørgen Amdahl of the Norwegian University of Science and Technology during the course of this study are also appreciated. 


\section{REFERENCES}

[1] Sharma JN, Dean RG. Second-order directional seas and associated wave forces. Society of Petroleum Engineers 1981;129-140.

[2] Smith SF, Ahilan RV, Hoyle M, Swan C, Marcom M. The effects of new developments in wave modelling on jack-up loads. In: Proc. 20 ${ }^{\text {th }}$ Int. Conf. on Offshore Mechanics and Arctic Engineering, Rio de Janeiro 2001. OMAE2001/OFT-1275.

[3] Forristall, GZ., Wave crest distributions: observations and second-order theory. Journal of physical oceanography 2000;30(8):1931-1943.

[4] Walker, DAG., Taylor, PH., Eatock Taylor, R., The shape of large surface waves on the open sea and the Draupner New Year wave. Applied Ocean Research 2004; 26:73-83.

[5] Mirzadeh J, Kimiaei M, Cassidy MJ. Performance of an example jack-up platform under directional random ocean waves. Applied Ocean Research 2016;54:87-100.

[6] Agarwal P, Manuel L. Incorporating irregular nonlinear waves in coupled simulation and reliability studies of offshore wind turbines. Applied Ocean Research 2011;33:215-27.

[7] Van der Meulen MB, Ashuri T, van Bussel GJ, Molenaar DP. Influence of nonlinear irregular waves on the fatigue loads of an offshore wind turbine. In: The Science of Making Torque from Wind, Oldenburg, Germany 2012;1-10.

[8] Cassidy MJ, Eatock Taylor R, Houlsby GT. Analysis of jack-up units using a Constrained NewWave methodology. Applied Ocean Research 2001; 23:221-234.

[9] Cassidy MJ, Taylor PH, Eatock Taylor R, Houlsby GT. Evaluation of long-term extreme response statistics of jack-up platforms. Ocean Engineering 2002; 29(13):1603-1631.

[10] Tromans PS, Anaturk AR, Hagemeijer P. A new model for the kinematics of large ocean wavesapplication as a design wave. In: Proc. 1st Int. Offshore and Polar Engineering Conf., Edinburgh 1991;64-71.

[11] Taylor PH, Jonathan P, Harland LA. Time domain simulation of jack-up dynamics with the extremes of a Gaussian process. Journal of Vibration and Acoustics 1997;119(4):624-628.

[12] Cassidy MJ. Non-linear analysis of jack-up structures subjected to random waves. University of Oxford, UK; 1999 [D. Phil Thesis].

[13] Stansberg CT, Gudmestad OT, Haver SK. Kinematics under extreme waves. Journal of Offshore Mechanics and Arctic Engineering 2008;130:021010.

[14] Wheeler JD. Method for calculating forces produced by irregular waves. Journal of Petroleum Technology 1970;22(3):359-367.

[15] DNV. Environmental conditions and environmental loads, DNV-RP-C205. Norway 2010.

[16] Longuet-Higgins MS. The effect of non-linearities on statistical distributions in the theory of sea waves. Journal of Fluid Mechanics 1963;17:459-80.

[17] Sorehde T, Amdahl J, Eberg E, Hellan O, Holmås T. USFOS - A computer program for progressive collapse analysis of steel offshore structures, Theory manual. SINTEF Report STF71 F 880381993.

[18] ISO. Petroleum and natural gas industries - Site-specific assessment of mobile offshore units - Part 2: Jackups commentary and detailed sample calculation, ISO/TR 19905-2:2012. Switzerland 2012.

[19] Skallerud B, Amdahl J. Nonlinear analysis of offshore structures. England: Research Studies Press; 2002.

[20] Amdahl J, Johansen A, Svan G. Ultimate capacity of jack-ups considering foundation behaviour. In: Proc. 7th Int. Conf. on the Behaviour of Offshore Structures, Massachusetts 1994;347-359.

[21] Van Langen H, Wong P, Dean E. Formulation and validation of a theoretical model for jack-up foundation load-displacement assessment. Marine Structures 1999;12(4):215-230.

[22] Mirzadeh J, Kimiaei M, Cassidy MJ. A framework to efficiently calculate the probability of failure of dynamically sensitive structures in a random sea. Ocean Engineering 2015;110215-226. 


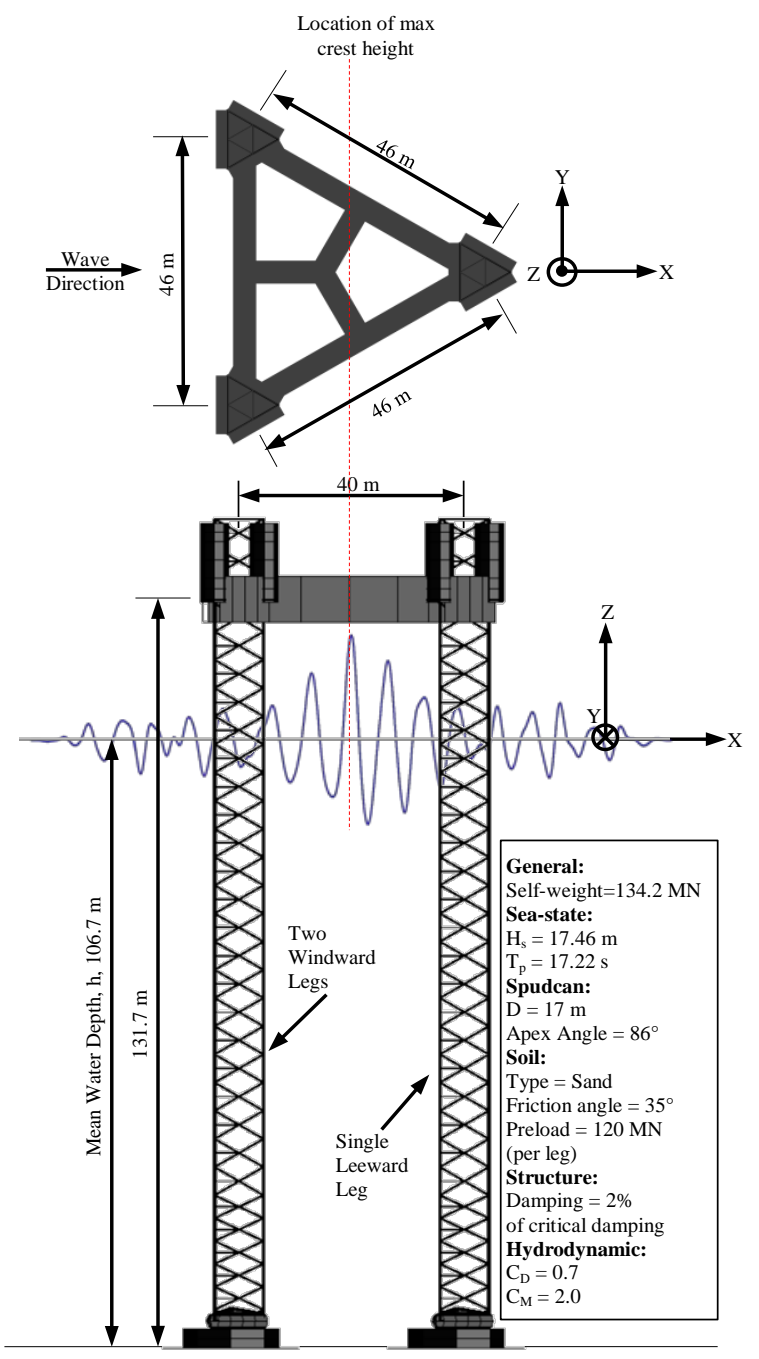

Figure 1. A general view of the sample jack-up platform 


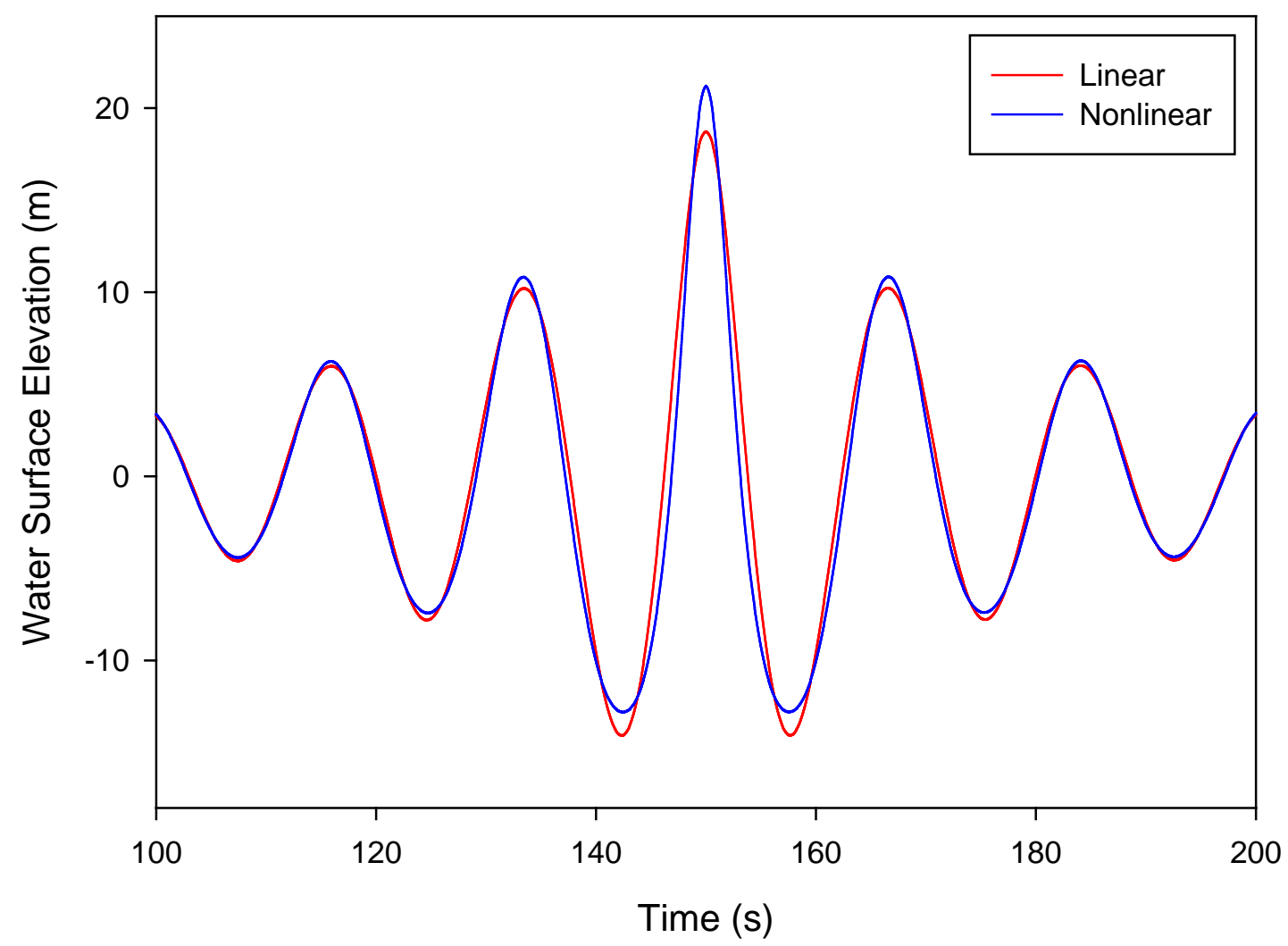

Figure 2. Time histories of the water surface for the linear and nonlinear NewWaves at $\mathrm{x}=0 \mathrm{~m}$ 


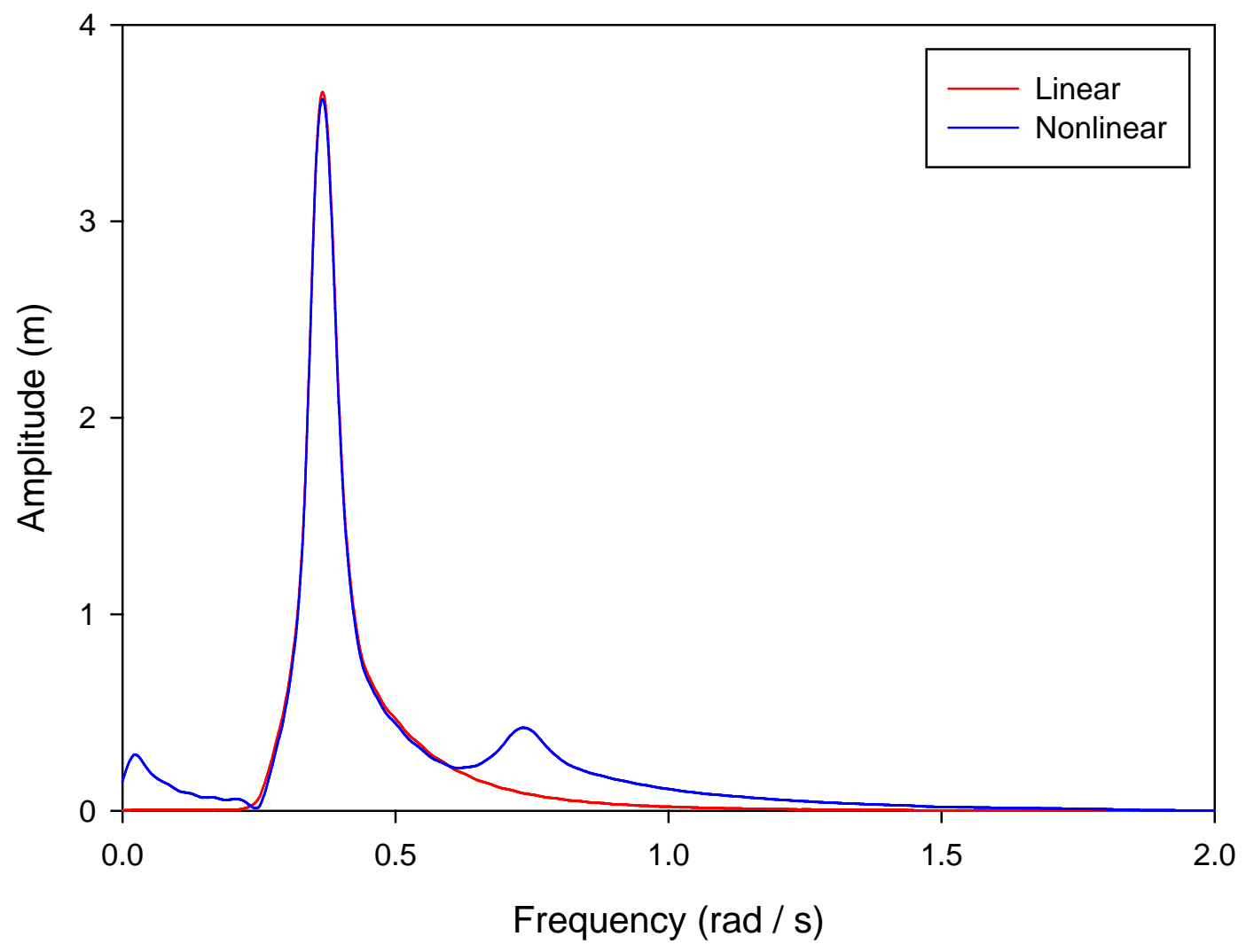

Figure 3. Amplitude Spectra of the simulated linear and nonlinear NewWave water surfaces at $\mathrm{x}=0 \mathrm{~m}$ 


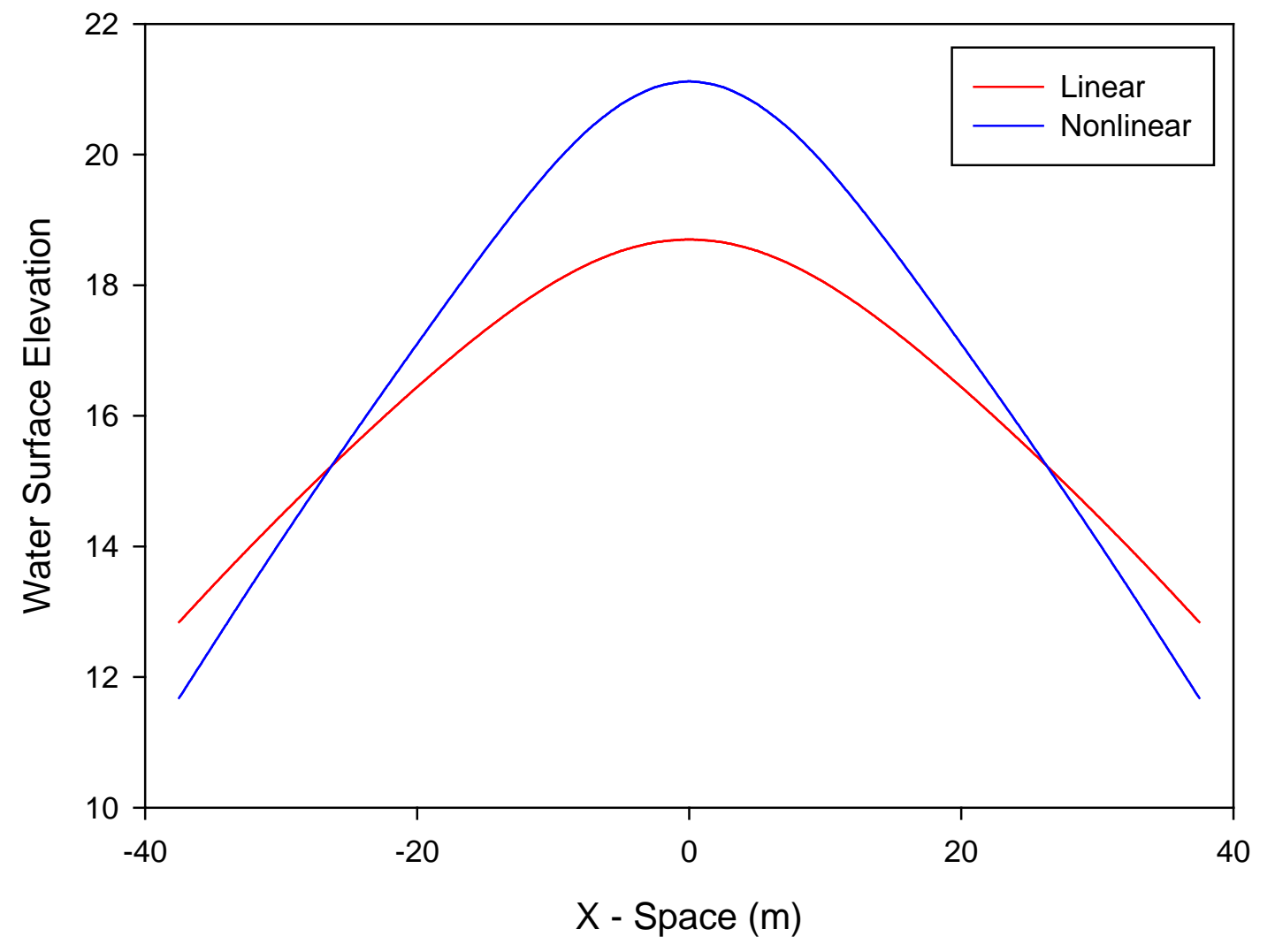

Figure 4. Space plot of the linear and nonlinear NewWave surface elevations at the time of the maximum crest $(\mathrm{t}=150 \mathrm{sec})$ 


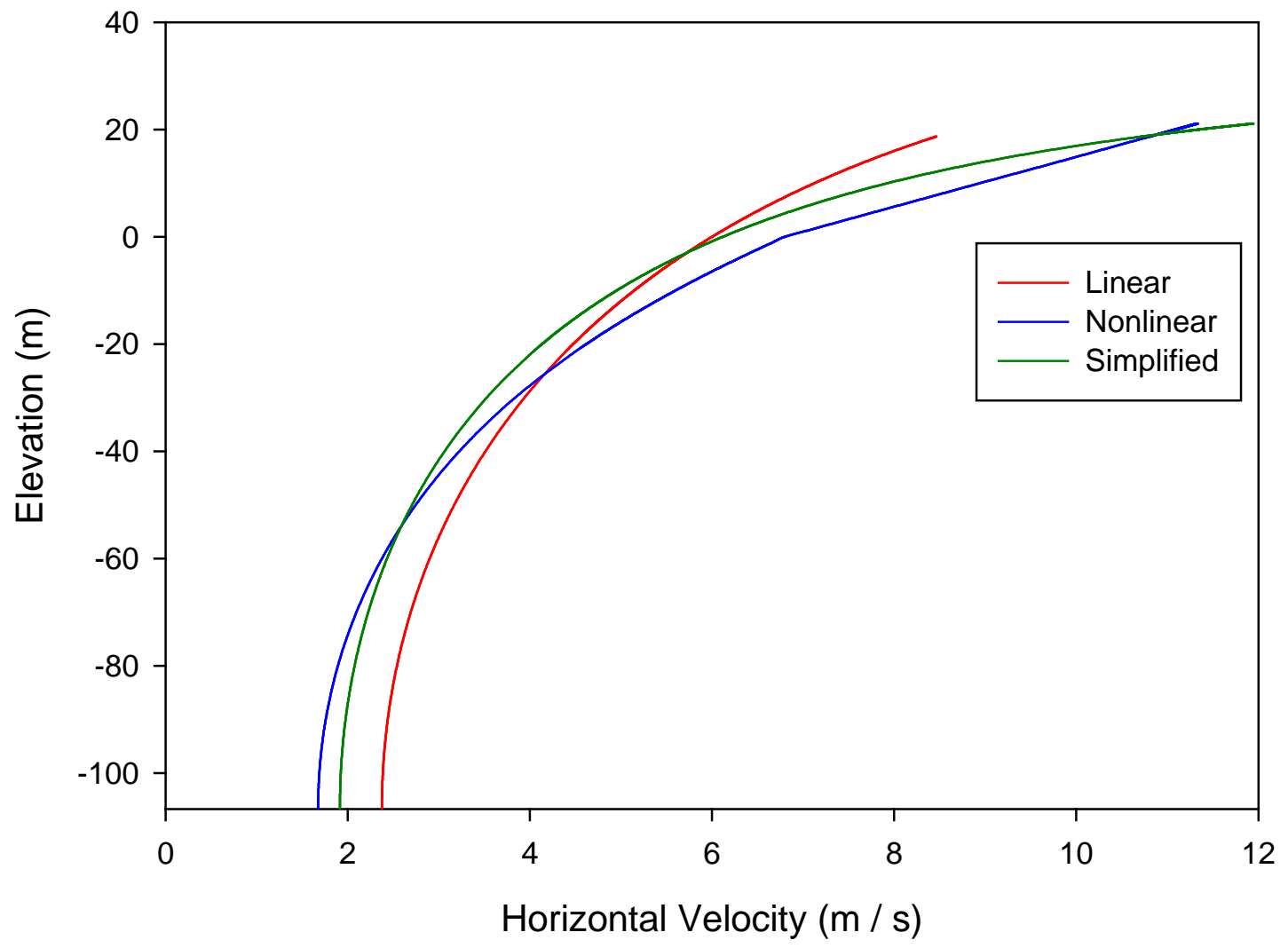

Figure 5. Horizontal velocity profiles of the linear, nonlinear and simplified NewWaves at the maximum crest location 

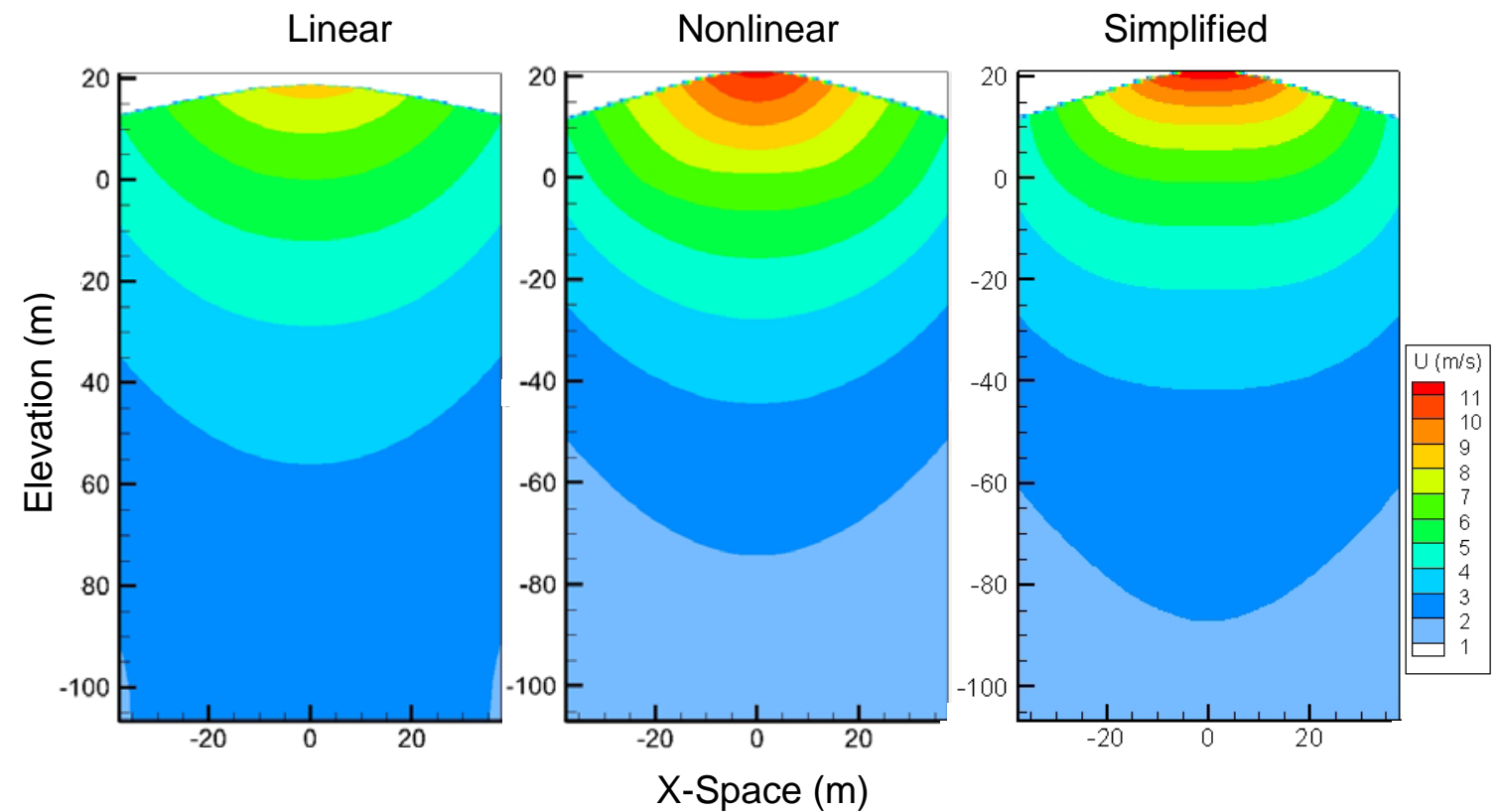

Figure 6. Space domain of the horizontal velocity for the linear, nonlinear and simplified NewWaves at the maximum crest 


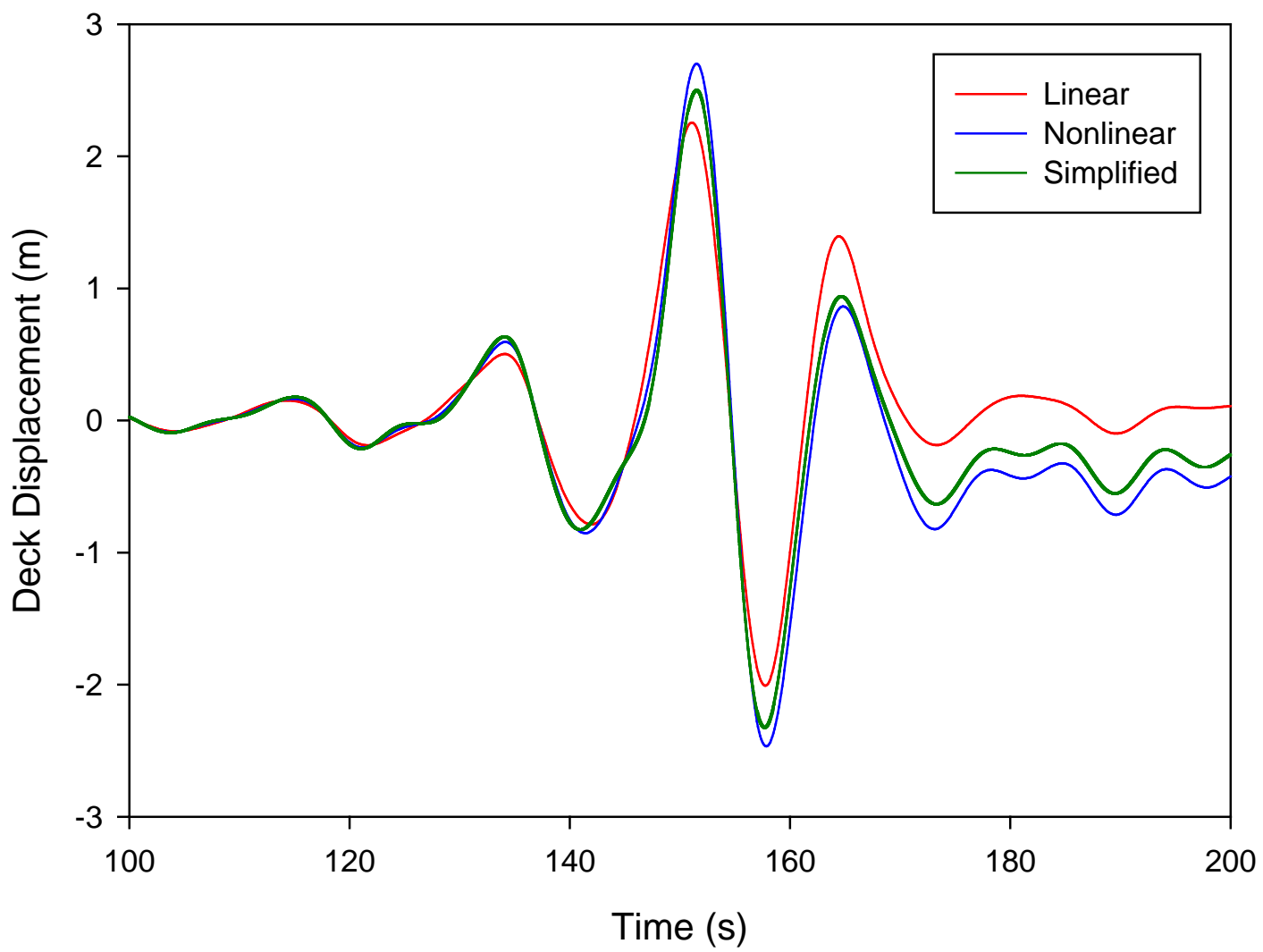

Figure 7. Comparison of the time histories of the deck displacement of the linear, nonlinear and simplified NewWaves 


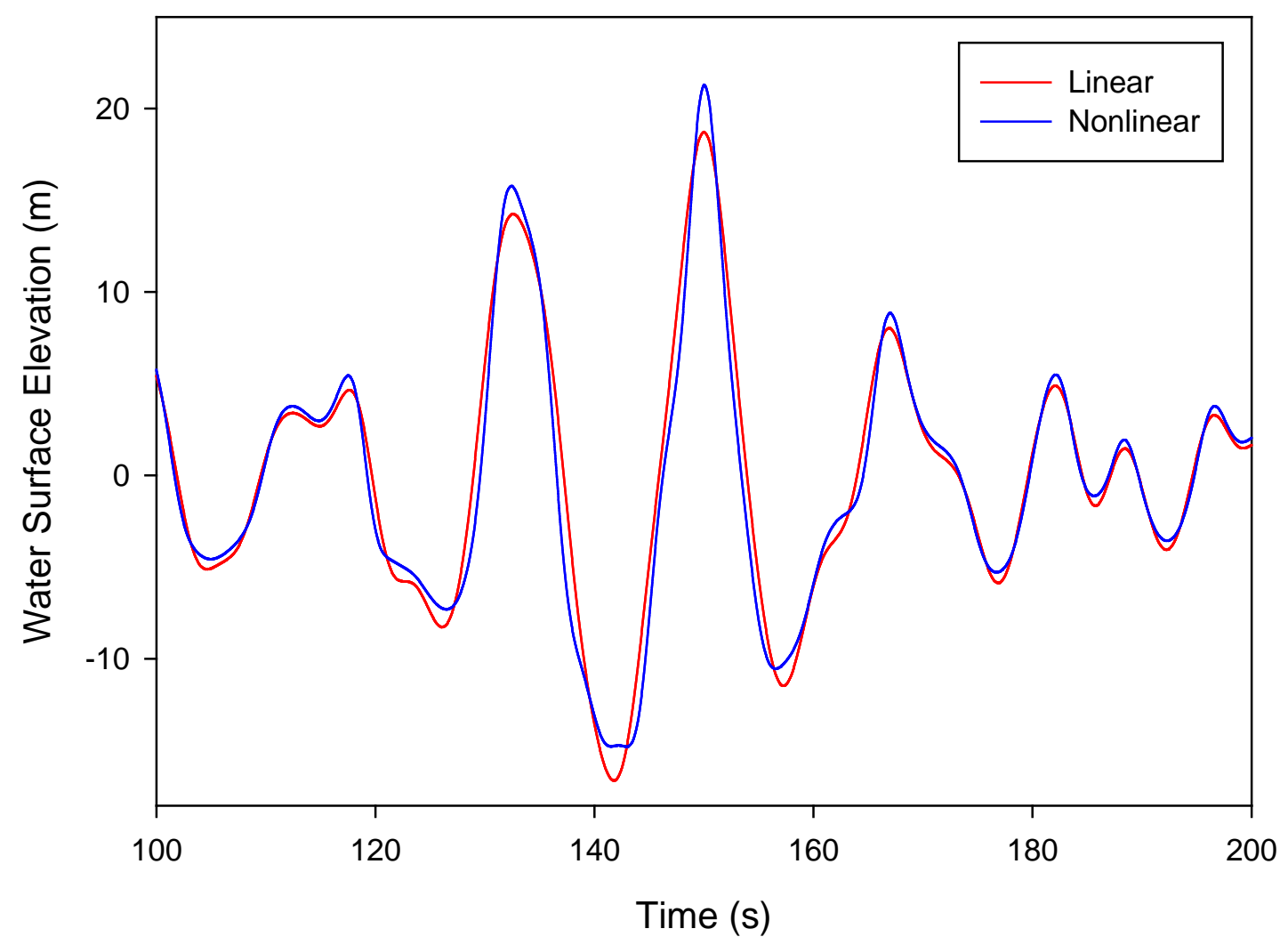

Figure 8. Time histories of the water surface for a sample linear and nonlinear $\mathrm{CNW}$ at $\mathrm{x}=0 \mathrm{~m}$ 


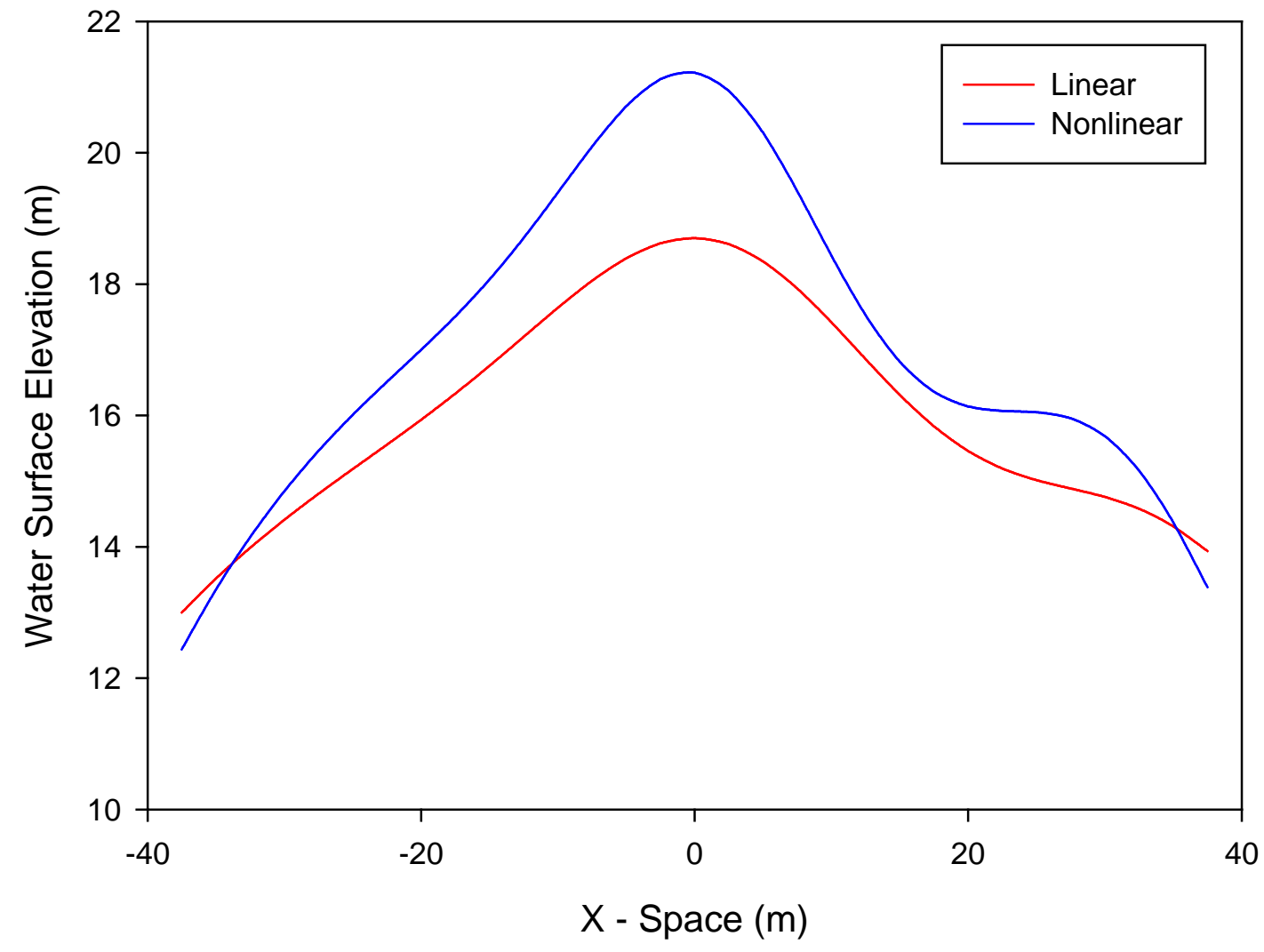

Figure 9. Surface elevation space plot for a sample linear and nonlinear CNW at the time of the maximum crest $(\mathrm{t}=150 \mathrm{sec})$ 


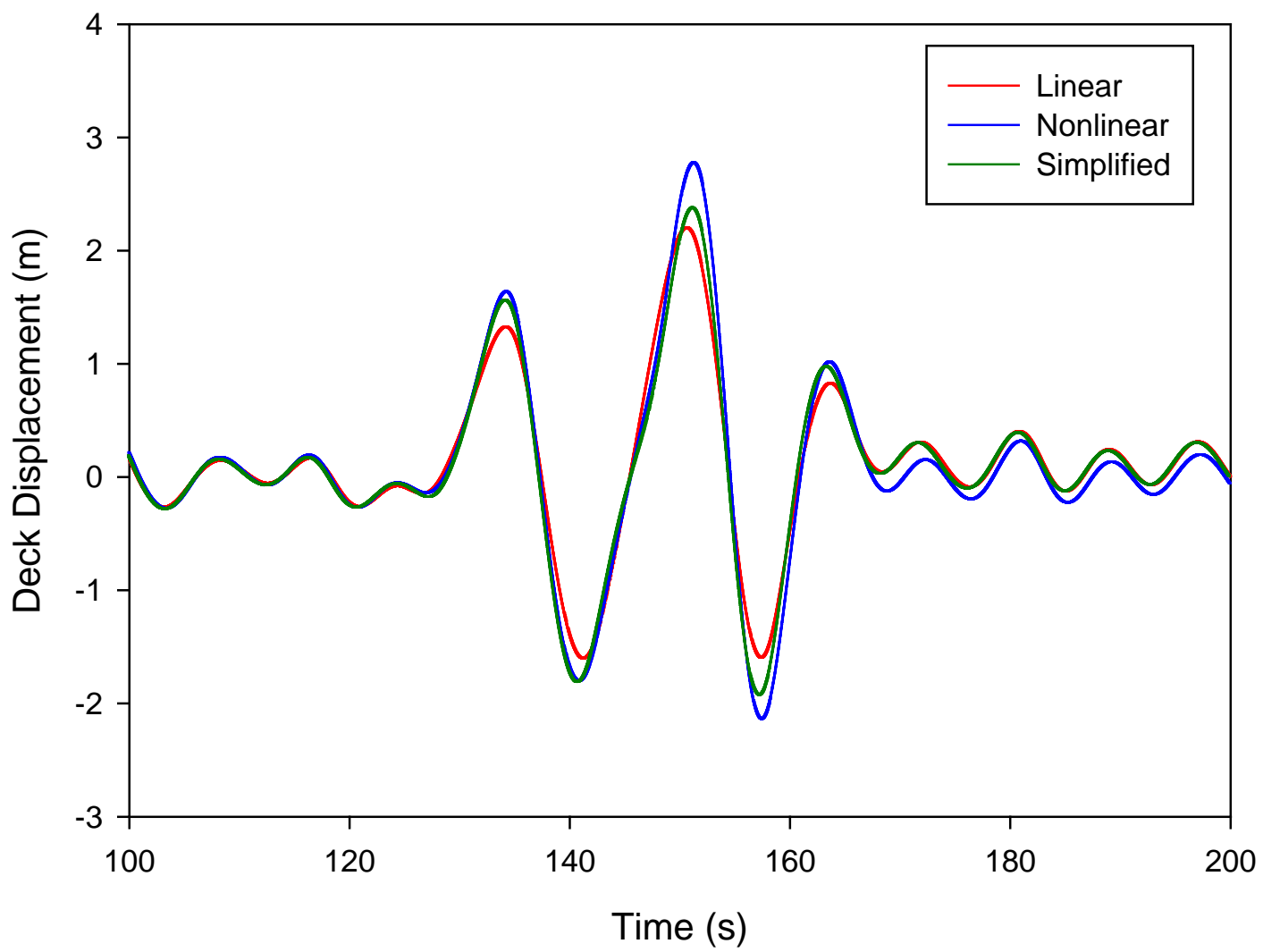

Figure 10. Comparison of the time histories of the deck displacement of the linear, nonlinear and simplified CNWs 


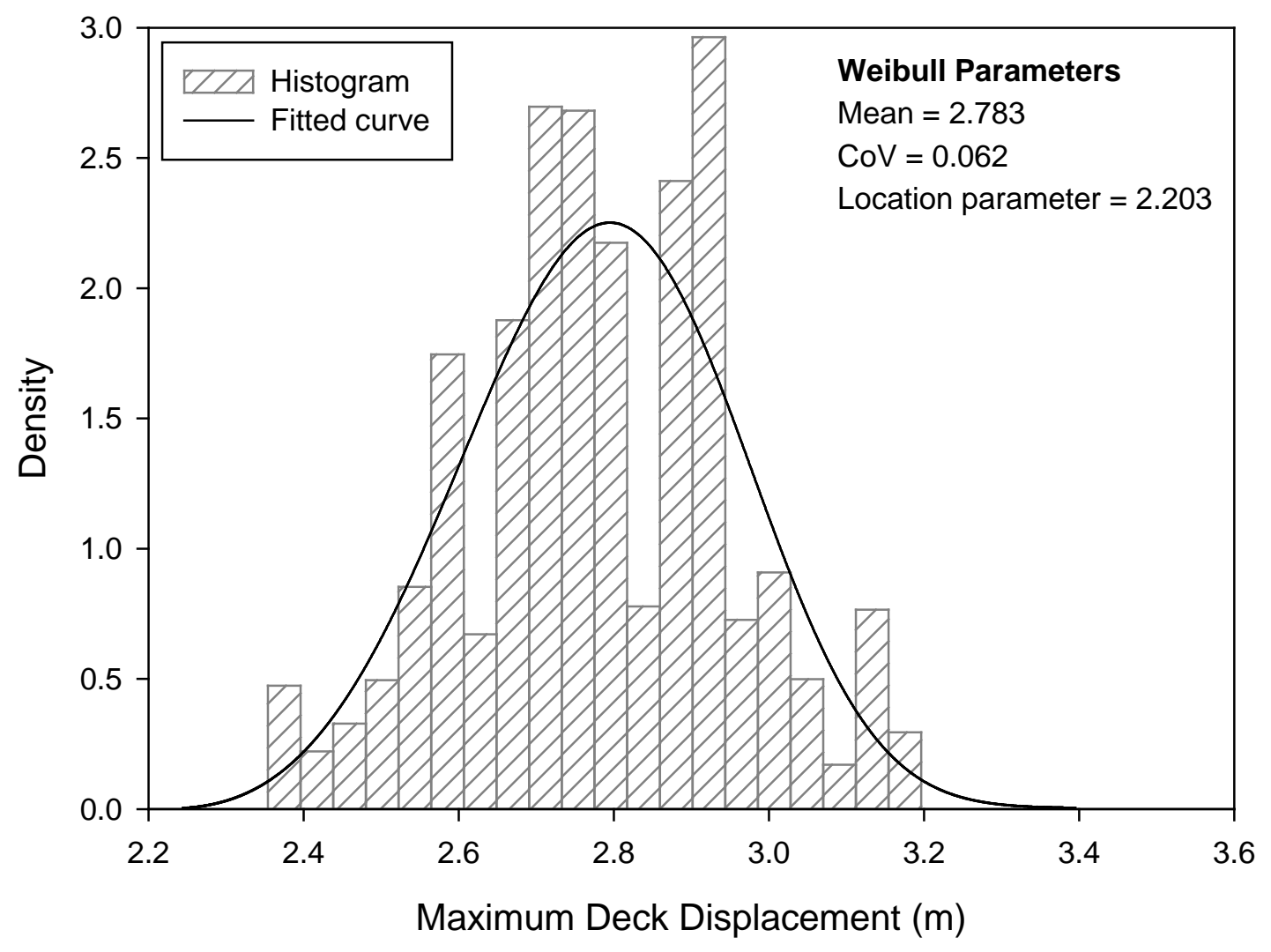

Figure 11. Weibull distribution of the maximum deck displacement for 102 nonlinear CNWs 


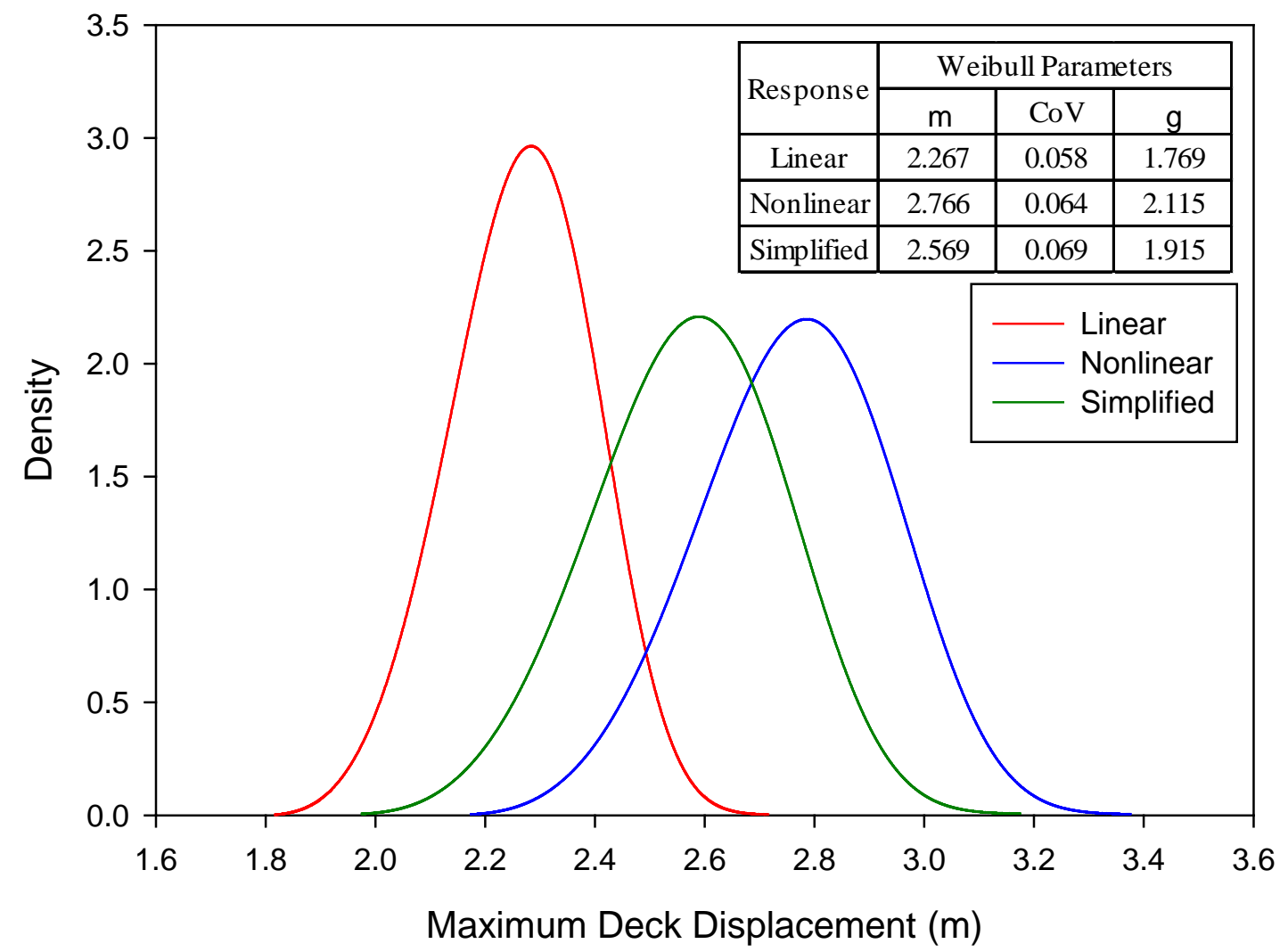

Figure 12. Comparison of the maximum deck displacement distributions of the linear, nonlinear and simplified CNWs 


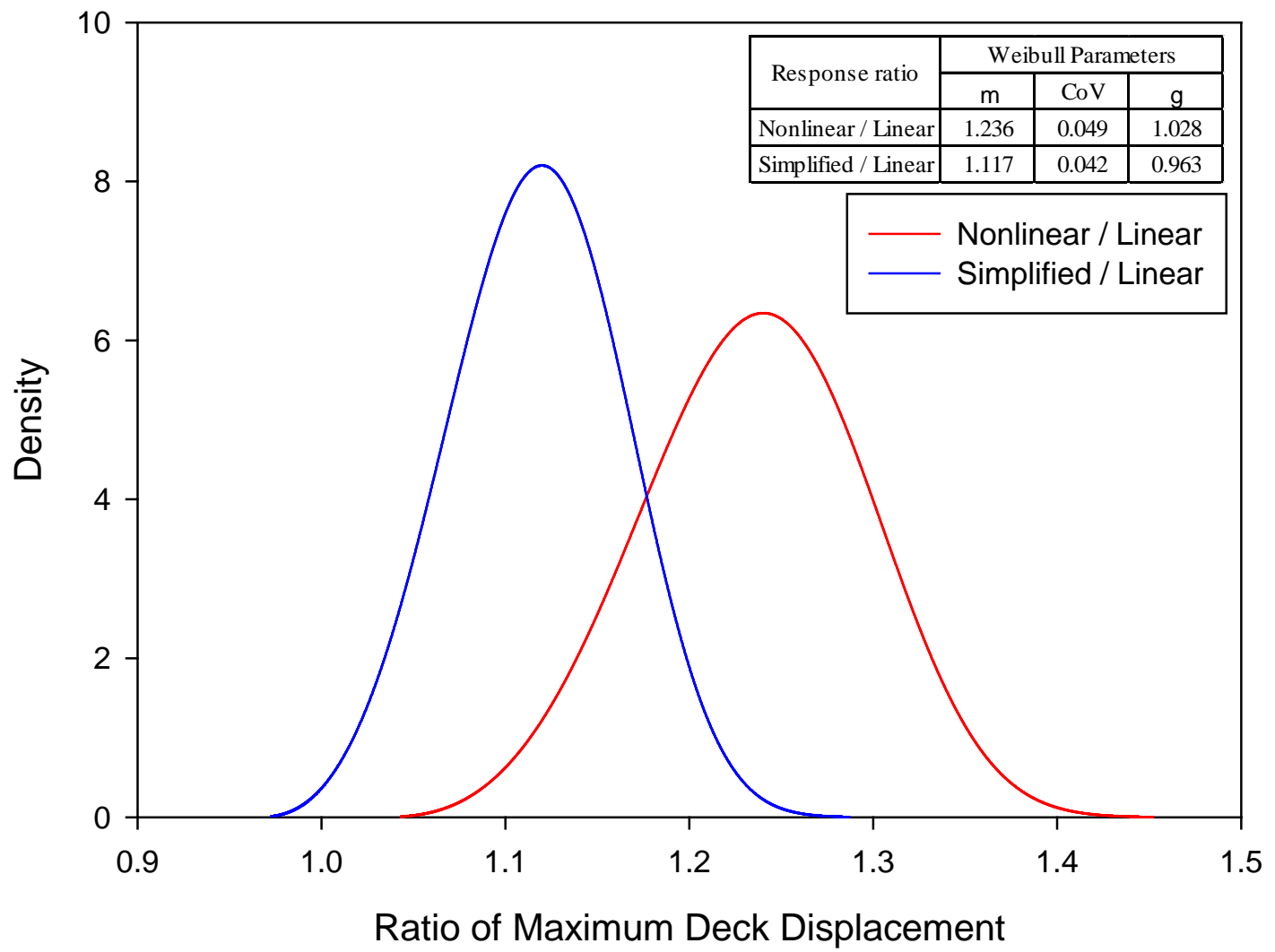

Figure 13. Distributions of the ratio of the maximum response from the nonlinear and simplified to the linear CNWs 


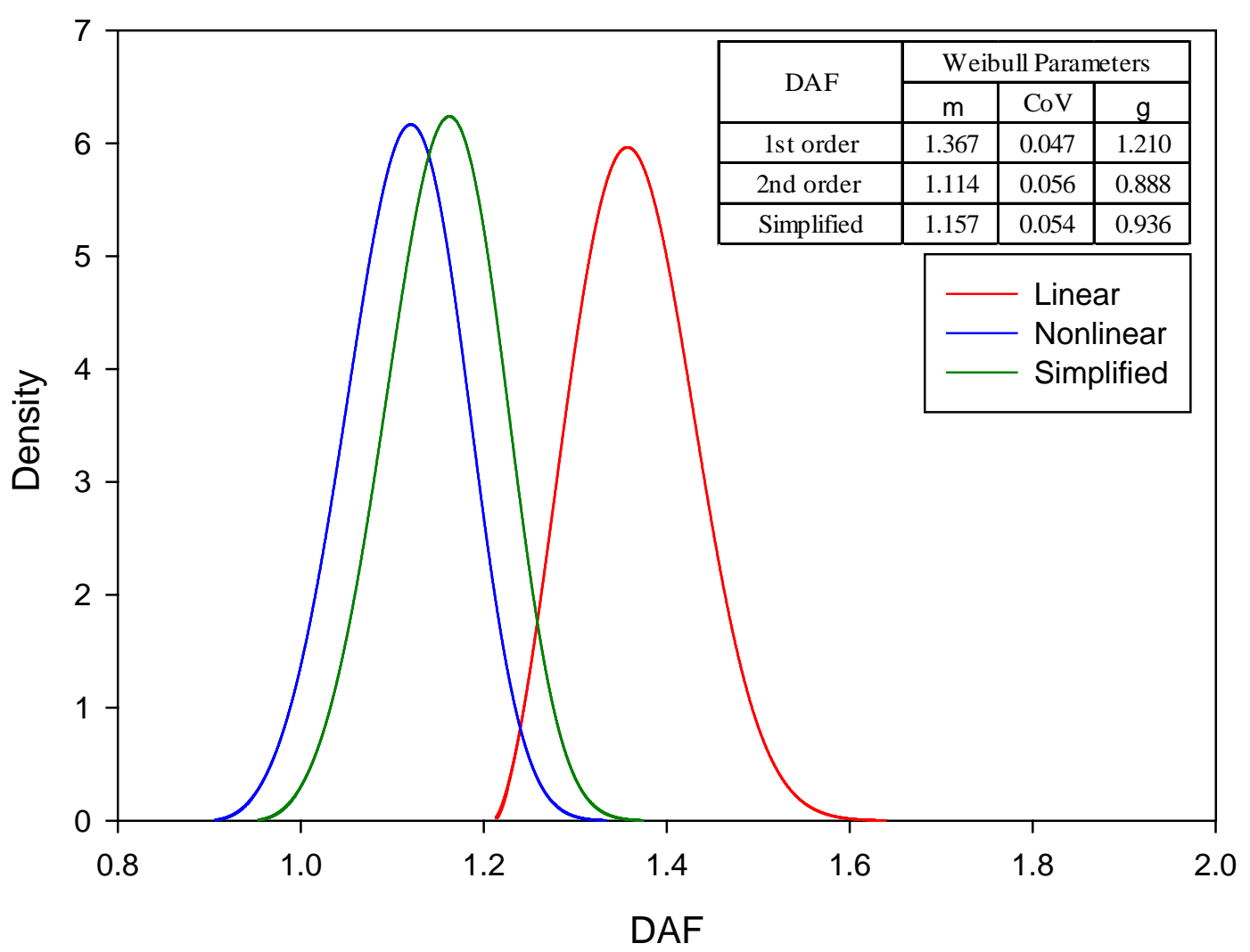

Figure 14. Comparison of the DAF distributions of the linear, nonlinear and simplified CNWs 